\title{
Z

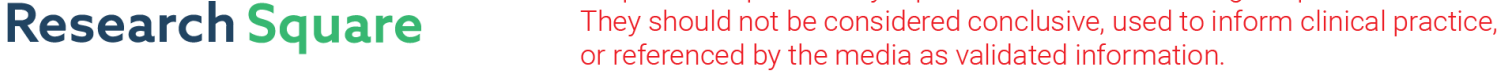 \\ Global mitigation efforts should prioritize support to the emerging emitters
}

Dabo Guan ( $\square$ guandabo@tsinghua.edu.cn )

Department of Earth System Science, Tsinghua University, Beijing, China.

\section{Can Cui}

Department of Earth System Science, Tsinghua University

\section{Daoping Wang}

Shanghai University of Finance and Economics https://orcid.org/0000-0001-5221-4965

\section{Vicky Chemutai}

The World Bank

\section{Paul Brenton}

The World Bank

\section{Shaohui Zhang}

Beihang University https://orcid.org/0000-0003-2487-8574

\section{Qiang Zhang}

Tsinghua University https://orcid.org/0000-0002-8376-131X

\section{Steven Davis}

University of California, Irvine https://orcid.org/0000-0002-9338-0844

\section{Physical Sciences - Article}

Keywords: climate change, $\mathrm{CO} 2$ emissions, energy, carbon growth

Posted Date: April 9th, 2021

DOl: https://doi.org/10.21203/rs.3.rs-376475/v1

License: (c) (1) This work is licensed under a Creative Commons Attribution 4.0 International License. Read Full License 


\section{Abstract}

International efforts to avoid dangerous climate change have historically focused on reducing energyrelated $\mathrm{CO}_{2}$ emissions from countries with either the largest economies (e.g., the EU and the U.S.) and/or the largest populations (e.g., China and India). However, in recent years, emissions have surged among a different, much less-examined group of countries, raising concerns that a next generation of high-emitting economies will obviate current mitigation targets. Compounding the limited analyses of these emerging emitters, the long-term effects of the COVID-19 pandemic on economic activity and energy systems remain unclear. Here, we analyze the trends and drivers of emissions in each of the 59 countries where emissions 2010-2018 grew faster than the global average (excluding China and India), and then project their emissions under a range of pandemic recovery and longer-term energy scenarios. Although future emissions diverge considerably depending on responses to COVID and subsequent pathways, we find that emissions from these countries combined nonetheless reach 5.4 to $6.6 \mathrm{Gt} \mathrm{CO}_{2}$ by 2040 in all our scenarios-substantially in excess of emissions from these regions in published scenarios that successfully limit global warming to $2^{\circ} \mathrm{C}$. Our results highlight the critical importance of ramping up mitigation efforts in countries that to this point have been largely ignored. Given the accompanying challenge of economic development and poverty reduction, this will require support from historically highemitting countries to decelerate emissions growth, including through considerable economic support and appropriate transfer of technologies that are required for transition to low carbon growth.

\section{Main Text}

Fossil fuel carbon dioxide $\left(\mathrm{CO}_{2}\right)$ emissions are the main cause of global warming. From around the 1990s, analyses of fossil emissions and Integrated Assessment Models (IAMs) have focused on a handful of industrialized economies where emissions have been high (US, EU) along with rapidlyindustrializing countries such as China and India ${ }^{1-4}$. To the extent that other countries have been included, they are typically aggregated into large and undifferentiated groups, such as "other developing countries" ${ }^{5}$ or "Rest Of World (ROW)." Yet since 2010 most of the growth in global emissions has been among these "ROW" countries. For example, all of the 59 countries whose annual emissions grew faster than the global nations' average 2010-2018 (hereinafter "emerging emitters") were developing economies, including many low-income countries ${ }^{6,7}$. Although none of these emerging emitters are individually large sources of emissions today, their combined emissions are greater than any single country except China and the U.S., and amount to 65\% more than India's annual emissions in 2018 (the world's third largest emitter). Thus, the success of international mitigation efforts may depend on these emerging emittersspecifically whether their goals of economic growth and human development are achieved using fossil energy.

In addition to the normal (i.e. large) uncertainties of socioeconomic and energy system trajectories, the SARS-CoV-2 (COVID) pandemic has dramatically affected human activities throughout the world, including economic activity, energy consumption and $\mathrm{CO}_{2}$ emissions ${ }^{8-10}$. For example, global $\mathrm{CO}_{2}$ 
emissions declined by nearly $5.8 \%$ in 2020 relative to that in $2019^{11}$. Yet there have been substantial differences among countries, including developing economies. For example, between January and October of 2020 per-thousand-people confirmed COVID cases and deaths in Peru were 27.3 and 1.04, respectively, while per capita cases over the same period in Vietnam were just $0.0121^{12}$. Future impacts of the disease and public health responses are unclear: vaccines are beginning to be distributed in some wealthy countries, but outbreaks and related economic impacts may yet persist for years among poorer countries $^{13}$, in turn affecting longer-term patterns of energy use and emissions there. It may therefore be particularly important in the context of low income countries, to understand the current public health situation and the policy, behavioral, and emissions responses during the pandemic period, i.e., 2020-2024.

Here, therefore, we systematically assess recent trends of emissions and their drivers among the 59 emerging emitters (defined as countries whose annual emissions 2010-2018 grew faster than (or similarly to) the average of all nations' $2 \%$, but excluding China and India), and then project future emissions from these countries under scenarios that span a range of near-term COVID impacts as well as longer-term socioeconomic and energy system trajectories. We separate the 59 countries from regional aggregations in major Intergrated Assessment Models (IAM) and update the Shared Socioeconomic Pathways (SSPs) based on recent emission pattern changes, in order to construct a country-specific future energy and emission dataset. Full descriptions of the datasets are available in Supplymentary Information. Details of our analytical approach are provided in the Methods. In summary, we first use index decomposition to analyze fossil fuel $\mathrm{CO}_{2}$ emissions data from the International Energy Agency (IEA) and characterize the drivers of each country's emissions. We then develop country-specific emissions scenarios using a Disaster Footprint Accounting Model ${ }^{14}$ based on the Adaptive Regional Input-Output (ARIO) Analysis ${ }^{10,15}$ (to capture changes in the pattern of countries' emissions due to COVID impacts on economic activities) for the period of 2020-2024. We then disaggregate each of the 59 countries from regional groupings of major IAMs and update the Shared Socioeconomic Pathways (SSPs) based on trends and drivers of these countries' recent emissions, to construct country-specific projections of their energy systems and emissions for the period 2025-2040. Full descriptions and details of these projections are available in Supplementary Information. Finally, we compare the limits of carbon space set by international climate targets with the magnitude of emissions from those emerging emitters and discuss the roles of other countries in cooperative emission mitigation.

\section{Emerging emitters}

Figure 1 compares the percent changes 2010-2018 in annual $\mathrm{CO}_{2}$ emissions and GDP (Gross Domestic Production) among the 59 emerging emitters (listed in Supplementary Data 1). The average annual growth rate of emissions of the 59 countries 2010-2018 was $6.2 \%$-much higher than the $2.0 \%$ average of all nations worldwide, and also higher than the $4.6 \%$ annual growth rate of these same countries' GDP, reflecting rising carbonization of their economies. Located in Asia, Africa, and Latin America, individually these countries emitted between 0.7 and $542.9 \mathrm{Mt}$ (million tons) $\mathrm{CO}_{2}$ in 2018 (bounded by Eritrea and Indonesia, respectively; Fig. 1). However, together the countries' emissions grew by $40.7 \%$ over the period, 
from 2.7 Gt (gigatons) to $3.8 \mathrm{Gt} \mathrm{CO}_{2}$. In comparison, emissions in China, the U.S., and India were 9.6, 4.9, and $2.3 \mathrm{Gt} \mathrm{CO}_{2}$ in 2018 . Moreover, the $1.1 \mathrm{Gt}$ increase in emissions accounts for $38.9 \%$ of the global increase in emissions over the period.

The emerging emitters include countries in development categories ranging from the least developed country (LDC) to economy in transition (EIT $)^{7}$, but in most cases with levels of GDP per capita substantially less than the global average (53 countries with per capita GDP less than 11,000 in constant 2010 USD). 698 million people in these countries lived in absolute poverty (e.g. $<1.9$ US\$ per day in purchasing power parity value) in 2017 , which accounts for $9.3 \%$ of global population ${ }^{16}$. Among the 59 countries, emissions grew faster than GDP in 34 (58\%), and twice as fast as GDP in 12 of these (20\%; Fig. 1). In 25 others (42\%), economic growth outstripped emissions growth, corresponding to decreasing carbon intensity of those economies.

\section{Drivers of recent emissions surge}

Figure 2 shows the drivers of changes in emissions 2010-2018 for 20 emerging emitters in Africa, Latin America and Asia. Analogous plots for the other 39 countries are shown in Supplementary Section 2.2 (Figure S5-S8). In each case, we plot the 2 most influential drivers spurring emissions growth as well as emissions reductions. Across all 59 emerging emitters, population growth (red) is most important in $29 \%$ of the countries including Uganda (Fig. 2a) and Lebanon (Fig. 2d), though increases in GDP per capita (lavender) are the foremost driver of emissions increases in $44 \%$ including Ethiopia, Colombia and Vietnam (Figs. 2e, $2 \mathrm{f}$ and $2 \mathrm{~g}$ ). Following closely behind these socioeconomic factors are increases in use of a particular fossil fuel; increases in either oil (orange) or coal (light orange) are the most influential factor of emissions increases in $14 \%$ of the 59 countries, including Sudan, Haiti, Myanmar, Guatemala and Kyrgyzstan (Figs. 2i, 2j, 2k, 2b4, and 2n, respectively; for emissions by fuel type, see Fig. S3). Energy intensity (turquoise) increases drove $12 \%$ of the countries' emissions growth as the top-two drivers, including Algeria and Laos (Figs. $2 \mathrm{~m}$ and 2o). Less commonly, increases in share of industrial value added in GDP (dark blue) are the second-most important driver of emission increases (in 7\% of the 59 countries) in Ethiopia (Fig. 2e), Haiti (Fig. 2j), etc. A rise in $\mathrm{CO}_{2}$ emissions intensity of energy use contributed most to $5 \%$ of the countries' emissions growth, including Nicaragua, Botswana and Nepal (Figs. 2q, 2r, and 2s, respectively). In comparison, a decline in energy intensity is the most influential driver of emissions reduction in a third (32\%) of the countries including Uganda, Mongolia, Ethiopia, and United Arab Emirates), followed by drops in $\mathrm{CO}_{2}$ emissions intensity of energy use (in $20 \%$ of the countries including Peru, Sudan and Haiti), a smaller share of industrial value added especially in Latin American and Other Asian countries in 15\% (Fig.2f, 2n, 2h, and 2t), and declining share of oil use (in $15 \%$ of the countries, including Botswana and Nepal). We describe the drivers of case countries' emissions in greater detail in Supplementary Section 2.3 and Fig. S9-14.

\section{Projections of future emissions}


In general, the 59 emerging emitters prioritize economic development to increase incomes and reduce poverty. In turn, GDP per capita is routinely a key driver of emissions increases (Fig. 2). Without offsetting decreases in the carbon intensity of these countries' economies, such development will continue to spur growth of emissions in the future. The economic disruption of the COVID pandemic and recovery will strongly affect economic growth and energy use over the next several years, with longer-term trajectories determined by development and energy pathways. Figure 3 shows projected emissions for selected emerging emitters, as well as the sum of all emerging emitters (Fig. 3a; supporting data for all emerging emitters are included as Supplementary Section 3.2 and 3.3). In each case, these projections include: a "baseline" scenario (pale blue curves) that represents a counterfactual world in which the COVID pandemic had not occurred and countries developed according to their current policy ambitions thereafter (i.e. following the SSP2 "middle of the road" pathway ${ }^{17}$ ); a "default lockdown" scenario (dashed red curves, 2020-2024) that assumes two COVID-related lockdowns with more targeted restrictions in the second (see Methods for further description including of other "mild" and "severe" COVID scenarios not shown in Fig. 3 but included in Fig. 4; see also Supplementary Section 2.3); a "weak policy" scenario (dark red curves) in which post-2024 emissions reflect current policy ambitions (SSP2) but reflect a lower starting point due to COVID. Fossil fuel based electricity generation and transportations are the largest emission sectors for the emerging emitting countries. In 2018 they accounted for $64.2 \%$ of total emission in Vietnam and $52.5 \%$ of Ethiopia (see Supplementary Fig. S4). We design a low-carbon scenario ("LC", dashed orange curves) that assumes new electricity-generating capacity installed after 2025 will increasingly be non-emitting and new vehicles after 2030 will increasingly be electric; and an extreme lowcarbon scenario ("Extreme LC", dashed green curves) that assumes all new electricity-generating capacity installed after 2025 will be non-emitting and all new vehicles after 2030 will be electric (for complete scenario settings, see Supplementary section 1.1, 1.2 and Fig. S1). These ambious low carbon scenarios sketch the best decarbonization effort can be made by emerging emitters (see Supplementary Fig. S2).

Although the modeled effects of COVID may be substantial, our scenarios suggest emissions from emerging emitters will increase in the coming decades, and in all cases the combined total exceeds $5 \mathrm{Gt}$ $\mathrm{CO}_{2}$ per year by 2040 (Fig. 3a). The combined annual emissions of the countries are between 5.4 and 6.6 $\mathrm{Gt} \mathrm{CO}_{2}$ in 2040 (Fig.3a), bounded by the extreme low-carbon scenario at the lower end and weak policy scenario at the upper end. Where low-carbon technologies are phased in gradually after 2025 (LC scenario), the combined emissions of these countries are reduced by $698 \mathrm{Mt} \mathrm{CO}_{2}(-10.6 \%)$ relative to the $6.6 \mathrm{Gt} \mathrm{CO}_{2}$ in the weak policy scenario (Fig.3a). In the extreme low-carbon scenario, the reduction in emissions is $1.1 \mathrm{Gt}(17.2 \%)$ relative to the weak policy scenario (Fig.3a). But even under this highly ambitious scenario, emissions continue to grow in 2040, calling into doubt that there are pathways for these countries to develop as also "climate friendly."

However, despite the increase in their combined emissions, there are important country-level differences in the emerging emitters' trajectories after the COVID shock. For example, in countries such as Peru and Vietnam, emissions continue to grow after 2023 but slows markedly after 2030 in the low-carbon scenarios (Figs. 3b and 3c). By contrast, in countries like Myanmar, emissions grow steadily through 
2040 regardless of scenario (Fig. 3d), and in others (Ethiopia and Uganda) emissions accelerate (Figs. 3e and 3f). These increases occur despite progressive decarbonization of transport and electricity, driven instead by increases in emissions from industry, and fuel consumption by the residential and commercial sectors. Across countries, emissions reductions under the extreme low-carbon scenario are $15 \%-23 \%$ relative to the baseline, mainly reflecting the share of current emissions that is from coal-fired electricity and transportation.

From 2020 to 2040, we project cumulative $\mathrm{CO}_{2}$ emissions from the 59 emerging emitters will exceed 100 Gt (see Fig. S16 for comparison between our projections and those for SS1-SSP5 produced by different IAMs), except in the most severe COVID scenario followed by the extreme low-carbon pathway (see Fig.4a). Between 2020 and 2024, lockdowns and gradual recovery in the default COVID scenario reduce cumulative emissions from the emerging emitters by $0.9 \mathrm{Gt} \mathrm{CO}_{2}$ compared to the $16.2 \mathrm{Gt}$ emitted in the baseline no-COVID scenario. In comparison, the extreme low-carbon scenario results in an almost tenfold greater reduction in cumulative emissions among these countries 2024-2040, 8.5 Gt. Yet even under this most ambitious decarbonization, the magnitude of emissions we project from these emerging emitters will strain the limits of the remaining budget of emissions that would avoid $1.5^{\circ} \mathrm{C}$ warming ${ }^{18}$, leaving very limited carbon space for other countries (Fig. S15). Fast carbonization of the 59 emerging emitters would require significant space by 2040 and leaves small room for other countries if we aim at achiving any climate target set in international agreements. This implies today's largest emitters would have to achieve net-zero $\mathrm{CO}_{2}$ emissions by $2040^{19}$. If the emerging emitters continue growing at the speed under the weak-policy scenario ( $+2.4 \%$ per year), achieving the global target of $1.5^{\circ} \mathrm{C}$, will require the rest of the world to reduce their emissions at an annual rate of $14.1 \%$ over $2020-2040$ (8.2\% per year for limiting warming below $2^{\circ} \mathrm{C}$, see Fig. $4 \mathrm{~b}$ ). Even if the emerging emitters are able to follow the Extreme LC pathway as we assumed $\left(+1.2 \%\right.$ per year) and global warming were to be limited below $1.5^{\circ} \mathrm{C}$, the rest of the world will have to reduce emissions by $13 \%$ per year over $2020-2040$ (7.6\% per year for $2^{\circ} \mathrm{C}$ limit).

\section{Discussions And Conclusions}

The developing countries we identify as emerging emitters account for a tiny share of cumulative fossil fuel $\mathrm{CO}_{2}$ emitted since the industrial revolution. Each of those countries still accounts for less than half percent of the world emission total. However, together, they have dominated the growth of such emissions over the past decade, and will influence the ultimate total. The COVID pandemic has had a major impact on economic development in many of these countries, and as many as 100 million people worldwide may be pushed into extreme poverty as a result ${ }^{20}$. Economic recovery and related investments in energy infrastructure are likely to set the carbon intensity of these countries for decades to come ${ }^{21}$. Indeed, our results suggest that COVID-related emissions reductions will be fleeting, and that the longerterm trajectories of emissions will depend upon climate and energy policies as these countries' economies resume growing. Yet sustained economic growth, crucial for poverty reduction, as well as projected increases in population will continue to drive growth in $\mathrm{CO}_{2}$ emissions in these countries, even assuming rapid uptake of low-carbon energy technologies for electricity generation and transportation. 
Robust future country-specific socioeconomic and emission pathway projections should be implemented, rather than the usual aggregation to the 'ROW' in most scientific research and climate talks.

Further reductions in these countries future emissions will thus require efforts beyond the electricity and transportation sectors, including changes in their economic structure, industrial production technologies, and broader energy sectors. For example, in countries where industry drives most of the growth in emissions, efforts might target less emissions-intensive economic activities, and in countries where energy consumption is a major driver, energy efficiency and lowering emission intensity will be key. It should be noted, though, that the low-carbon scenarios we designed are not likely to be achieved in these countries without substantial further decreases in the costs of electric vehicles and renewable electricity. In turn, these scenarios probably imply considerable economic support and technology transfer from higher-income countries, even as those more affluent countries and other major developing countries (e.g., the BRICS) must peak their emissions in the near future and drastically reduce their own emissions thereafter to meet international climate goals. As such, emphasis on supporting trade policies which liberalize trade in these environmentally-friendly goods will be critical. Indeed, emissions from emerging emitters-which we project will still be rising in 2040-may need to be entirely offset by negative emissions to limit the increase in global temperature to well below $2^{\circ} \mathrm{C}$. Climate change is a typical public goods. More advanced countries should assist emerging emitting countries by sharing energy-saving technologies and knowledge about renewable energy. As the "world factory" could most likely remain in less-developed countries, the demand from consumers in the developed world inevitably drives the global emission surge. From this perspective, a low-carbon lifestyle all over the world benefits global emission reduction.

\section{Methods}

\section{Emission drivers: index decomposition analysis.}

We divide the emissions growth (C) over 2010 to 2018 into contributions of six drivers: $C_{P}$ from population $(P)$ growth; $C_{G}$ from economic growth measured by GDP (G) per capita; $C_{I S}$ from industrial structure (IS), as the share of GDP of primary industry, secondary industry, and tertiary industry; $\mathrm{C}_{\mathrm{El}}$ from energy intensity (EI) that is energy consumption (E) per unit of GDP; $C_{E S}$ from energy structure (ES), as the share of consumption of energy types including coal, oil, natural gas, and other types; and $\mathrm{C}_{\mathrm{Cl}}$ from $\mathrm{CO}_{2}$ emissions intensity $(\mathrm{Cl})$ that is emissions per unit of energy consumption, as follows: 


$$
C=\sum_{i j} P \times \frac{G}{P} \times \frac{G_{i}}{G} \times \frac{E_{i}}{G_{i}} \times \frac{E_{i j}}{E_{i}} \times \frac{C_{i j}}{E_{i j}}=\sum_{i j} P \times G \times I S_{i} \times E I_{i} \times E S_{i j} \times C I_{i j}
$$

Where, $i$ refers to the $i$ th industry in primary industry, secondary industry, and tertiary industry; $j$ refers to the $j$ th energy type in coal, oil, natural gas, and other types. The change in C from time 0 to time $\mathrm{T}$ can be divided into six parts using logarithmic mean Divisa index (LMDI) method ${ }^{22,23}$ as follows:

$$
\Delta C=C^{T}-C^{0}=\Delta C_{P}+\Delta C_{G}+\Delta C_{I S}+\Delta C_{E I}+\Delta C_{E S}+\Delta C_{C I}
$$

where:

$$
\Delta C_{X}=\sum_{i j} \frac{C_{i j}^{T}-C_{i j}^{0}}{\ln C_{i j}^{T}-\ln C_{i j}^{0}} \times \ln \left(\frac{X_{i j}^{T}}{X_{i j}^{0}}\right)
$$

where, $X_{i j}$ refers to the driving factors, i.e. $P, G, I S_{i}, E I_{i}, E S_{i j}$, and $C I_{i j}$.

\section{Emission scenario settings for over 2020-2024 and 2024-2040.}

COVID lockdown assumptions over 2020-2024. We set three scenarios of lockdown from the dimensions of number of lockdowns, durations (number of weeks that lockdown measures are in place) and strictness, i.e. the percentage by which labour availability and transportation capacity are reduced relative to pre-pandemic levels. The period of 2020 - 2024 includes lockdown periods (e.g. 2020 - 2022) and economic recovery afterwards (2023-2024). Full descriptions of all scenarios and related assumptions are available at Supplementary Information section 1.1.3.

In summary, 1) the baseline scenario, where there is no COVID and countries develop under the present policy ambitions; 2) the default COVID scenario is designed on the basis of the literature and Google Mobility data (for all countries' $1^{\text {st }}$ lockdown in 2020), and three additional lockdowns over 2020-2022 ${ }^{13}$ but with easing off duration and strictness each time as we consider the learning effects and potential herd immunity, i.e. countries might achieve the same control effects of the pandemic with weaker strictness in future lockdowns (for details, see Supplementary section 1.1.3); 3) the mildest COVID lockdown scenario, where there is twice of lockdown over 2020-2022, with strictness of $2^{\text {nd }}$ lockdown cutting off by $60 \%$; 4 ) the severe COVID lockdown scenario, where there is eight lockdowns over 20202022 with slow easing off duration and strictness each time due to the learning effects (see Table S1 for specific settings of different scenarios).

Post-COVID scenarios over 2024-2040. After 2024 with every assumption of COVID impact, supposing the COVID is defeated and countries return to the normal development. In post-COVID era, after 2024, we evaluate three carbon pathways for each country. The Baseline scenario assumes no COVID-19 during 2020-2024 and further grow in line with SSP2 trend. The Weak Policy scenario set describes emissions growth of the post-COVID era in line with SSP2 development trend after default COVID lockdown. We also 
provide scenarios to illustrate emission consequences of the mild and the severe COVID lockdown impact by different development pathways, data shown in Supplementary Section 3.2 and 3.3. Considering the impact of COVID, this work updates the emission projections under the SSP2 scenario of the emerging emitters (for details and comparisons with SSP downscaled results, see Supplementary Section 2.4).

The two scenario sets of Low-Carbon represent levels of deployment of a highly ambitious low-carbon technologies scenario. Specifically, the LC assumes that the new electricity demand after 2025 is linearly covered by renewable energy sources or fossil fuel with carbon capture and storage (CCS; depending on whether the country's power sector is currently thermal-dominated, see Supplementary Section 1.2.2) and new vehicles after 2030 are linearly covered by electric vehicles. While the most optimistical scenario, the extreme LC, assumes all newly increased electricity demand after 2025 is met, right away, either by renewable energy sources or fossil fuel with CCS feature and all new vehicles after 2030 are battery electric.

\section{Emissions accounting over 2020-2040}

Considering the COVID-19 lockdown impact on $\mathrm{CO}_{2}$ emissions over 2020-2024. COVID-19 has caused economic setbacks across the world and will possibly last until $2024{ }^{24}$. In this work, we set the COVID period as 2020-2024, and modeled the economic activities and emissions over 2019-2024 (2019 is the pre-event reference year). The developed Disaster Footprint Model ${ }^{10,14}$ based on the Adaptive Regional Input-Output (ARIO) ${ }^{15}$ analysis (for details, see Supplementary section 1.1) is used to analyze the disaster-induced influence on regional economy by incorporating the production capacity constraints resulting from capital loss and changes of consumption behavior within pre- and post-disaster periods, as well as possibilities of over-production ${ }^{3,4}$. Here, we extended the model to a multiregional economic impact model, which has the ability to simulate the sectoral output of countries under different lockdown scenarios and its the propagation of the shocks across multiple regions. After calibrating the model with the latest GTAP database version $10^{7}$, we assess the dynamic impact of COVID-19 control measures on the global economy throughout production supply chains by considering available production imbalances and consumer behavior changes ${ }^{8}$.

Full method of the Disaster Footprint model is systematically presented in our early contributions ${ }^{14,25}$. The key equations and method descriptions are available at Supplementary section 1.1.1. In summary, our model is consisting of two types of agents, i.e., producers and households. In an economy, each sector can be regarded as a producer, in which labour and capital are the two main primary inputs for producing products. Meanwhile, economic sectors are also consumers that require intermediate products from other sectors. In pre-COVID, economic total output should satisfy intermediate demands and final demands from consumers. However, such economic balances are broken by the pandemic and further crush the supply chains. From the view of producer, restriction of labour input caused by COVID control measures (due to order of social distancing and closure of business) will decrease the production capacity and outputs. The reduction of any economic output will trigger cascading effects on the rest of 
the economy ${ }^{10}$. This makes labour constraints a key factor to consider in disaster impact analysis. We acknowledge that COVID containment measures have different effects on labor supply in different sectors. We set a specific impact to labor multipliers for each sector on the basis of three factors: exposure level of the sector's work, whether it is an essential sector, and whether it is possible to work at home. The proportion of surviving productive capacity from the constrained labour productive capacity can be estimated. The shortage of intermediate products will further affect the production capacity of downstream sectors and reduce their outputs due to supply chain forward effect. From the view of demand, business activities can be reduced when containment measures are in place, but consumption activities can be temporarily kept due to stock or via alternative suppliers. We build in both business stock and inventories and supply chain 'substitution effect' into our model to better reflect interregional and inter-sectoral dynamics of during economic recovery process.

The Disaster Footprint model stimulates weekly-step economic outputs for all sectors and countries, we estimate the emissions of countries based on their sectoral emission intensities and economic outputs under baseline scenario (no-COVID). In this work, we assume sectoral intensity has kept unchanged at 2019 level for the period of 2020-2024 as the production efficiency, technology level, and economic structures are unlikely to change significantly during pandemic (see full description in Supplementary Information section 1.1.1). The emissions data over 2020-2024 are calibriated to match historial trends. Procedures of data calibration and updates are provided in Supplementary section 1.1.2. We present all produced emission data 2020-2025 in Supplementary Data 2.

Country-level $\mathrm{CO}_{2}$ emissions trend for three scenarios in 2025-2040. We selected the SSP2 scenario (middle of the road, which can be seen as the business as usual trend) developed by IIASA's MESSAGE ${ }^{17}$ and GAINS model ${ }^{26-28}$ to provide $\mathrm{CO}_{2}$ emissions and energy mix projections for the 59 emerging emitters for our 'baseline (continues from no-COVID impact)' and 'weak policy' scenarios (with COVID impact). However, the GAINS model only covers major countries and regions, while more than half of emerging emitters studied here are aggregated into 'Other Regions' or 'Rest of World'. Among 59 emerging emitters, there are 24 countries' SSPs are available in GAINS database. For 35 out of 59 countries that future socioeconomic development trajectories are not available, thus, the downscaling and appropriate calibration approaches are used to project country-level emissions, according to the region-level emissions (see Supplementary section 1.2.1). We present all produced emission data 2025-2040 in Supplementary Data 3. We also provide full comparions between our calibrated data and direct downscaling data from SSPs produced by different IAMs (see Supplementary section 2.4, Fig. S16).

The LCT and ELCT scenarios are modified based on the emissions resulted from 'weak-policy' scenario. We simulate the application of CCS, renewable power generation and electric vehicle by considering the emission reduction rate of the low-carbon technologies. In the LCT scenario, the low-carbon technologies are assumed to be applied since 2025 (linearly increasing the application, and fully applied in 2040), including carbon capture and storage (CCS), renewable energy for the production of newly-demanded electricity (the differences are given in Post-COVID scenarios over 2024-2040.), and electric vehicles 
replacing the newly-increased oil fueled automobiles since 2030 (linearly increasing from 0 to $100 \%$ in 2040; the additional electricity demand are provided with LCTs in electricity sector). The low-carbon technologies are modeled by applying the total emission reduction rate of the low-carbon technologies to the corresponding sector's emissions, assuming other sectors' emissions remain as the baseline scenario. The total emission reduction rates of the CCS, renewable energy for power generation, and electric vehicle are set as $88 \%^{29}, 80 \%^{30,31}$ and $100 \%{ }^{32}$ according to literature, respectively.

\section{Data sources}

Historical data 2010-2018. $\mathrm{CO}_{2}$ emissions from fuel combustions and energy consumption data over 2010-2018 are from the International Energy Agency (IEA) ${ }^{6,33}$, covering data of over 140 countries by energy type and economic sector. The population and the GDP data, and the industrial structure data, i.e. the percentage of agriculture, forestry, and fishing, industry and services in value added are from the World Bank ${ }^{34}$.

Data for modelling emissions in COVID-19 period 2020-2024. The global multi-regional input-output (MRIO) table used in the model is compiled based on the latest GTAP database (version 10) ${ }^{35}$. GTAP database presents values of intermediate products transaction between 65 sectors, the output of each sector, and final consumption of commodities in 141 countries/regions. It also provides global bilateral trade links among the sectors and countries/regions. The historical emissions are collected from the IEA ${ }^{6}$. The emission intensities are calculated based on the emissions from the GAINS (Greenhouse Gas - Air Pollution Interactions and Synergies) model of IIASA ${ }^{26,36}$ and World Energy Model 2019 of IEA $^{37}$.

Data for post-COVID period 2025-2040. The no-COVID assumption data including sectoral value added, and the sectoral post-COVID energy mix data and $\mathrm{CO}_{2}$ emissions data are from the "No Policies Scenario" (NPS) projections of GAINS model from IIASA ${ }^{26}$. The $\mathrm{CO}_{2}$ emissions data, the population data, and the GDP data under SSPs are from the SSP Database (version 2.0) ${ }^{38-43}$.

Data for global warming of $1.5^{\circ} \mathrm{C}$ and $2^{\circ} \mathrm{C}$. The $\mathrm{CO}_{2}$ emissions data of countries under the $1.5^{\circ} \mathrm{C}$ and $2^{\circ} \mathrm{C}$ global warming scenarios are compiled from the Integrated Assessment Modeling Consortium (IAMC) $1.5^{\circ} \mathrm{C}$ Scenario ${ }^{44}$. The used data include the $\mathrm{CO}_{2}$ emissions of the world under $1.5^{\circ} \mathrm{C}$ and $2^{\circ} \mathrm{C}$ scenarios. For the emissions of the 59 emerging emitters, we use the emissions under the weak policy scenario. The emissions of the rest of the world are defined as the emissions of the world minus that of the 59 emerging emitters.

\section{References}

1. Raupach, M. R. et al. Global and regional drivers of accelerating $\mathrm{CO} 2$ emissions. Proceedings of the National Academy of Sciences 104, 10288-10293 (2007). 
2. Fernández González, P., Landajo, M. \& Presno, M. J. The driving forces behind changes in CO2 emission levels in EU-27. Differences between member states. Environmental Science \& Policy 38, 11-16 (2014).

3. Hubacek, K., Guan, D. \& Barua, A. Changing lifestyles and consumption patterns in developing countries: A scenario analysis for China and India. Futures 39, 1084-1096 (2007).

4. Cantore, N. \& Padilla, E. Equality and $\mathrm{CO} 2$ emissions distribution in climate change integrated assessment modelling. Energy 35, 298-313 (2010).

5. Winkler, H., Brouns, B. \& Kartha, S. Future mitigation commitments: differentiating among non-Annex I countries. Climate Policy 5, 469-486 (2006).

6. International Energy Agency. CO2 emission from fuel combustion. (2018).

7. United Nations. World Economic Situation and Prospects 2020. World Economic Situation and Prospects 163-170 (2020).

8. Le Quéré, C. et al. Temporary reduction in daily global CO2 emissions during the COVID-19 forced confinement. Nat. Clim. Chang. 10, 647-653 (2020).

9. Liu, Z. et al. Near-real-time data captured record decline in global CO2 emissions due to COVID-19. 45.

10. Guan, D. et al. Global supply-chain effects of COVID-19 control measures. Nature Human Behaviour 4, 577-587 (2020).

11. Liu, Z. et al. Near-real-time monitoring of global CO 2 emissions reveals the effects of the COVID-19 pandemic. Nature Communications 11, 5172 (2020).

12. Dong, E., Du, H. \& Gardner, L. An interactive web-based dashboard to track COVID-19 in real time. The Lancet Infectious Diseases 20, 533-534 (2020).

13. Kissler, S. M., Tedijanto, C., Goldstein, E., Grad, Y. H. \& Lipsitch, M. Projecting the transmission dynamics of SARS-CoV-2 through the postpandemic period. 10 (2020).

14. Wang, D. et al. Economic footprint of California wildfires in 2018. Nat Sustain 4, 252-260 (2021).

15. Hallegatte, S. An Adaptive Regional Input-Output Model and its Application to the Assessment of the Economic Cost of Katrina. Risk Analysis (2008).

16. World Bank, D. R. G. World Bank Open Data. (2021).

17. Fricko, O. et al. The marker quantification of the Shared Socioeconomic Pathway 2: A middle-of-theroad scenario for the 21st century. Global Environmental Change 42, 251-267 (2017).

18. Allen, M. et al. Global warming of $1.5^{\circ} \mathrm{C}$. An IPCC Special Report on the impacts of global warming of $1.5^{\circ} \mathrm{C}$ above pre-industrial levels and related global greenhouse gas emission pathways, in the context of strengthening the global response to the threat of climate change, sustainable development, and efforts to eradicate poverty. (2018).

19. Tong, D. et al. Committed emissions from existing energy infrastructure jeopardize $1.5^{\circ} \mathrm{C}$ climate target. Nature 572, 373-377 (2019). 
20. World Bank. Projected poverty impacts of COVID19. 1

http://pubdocs.worldbank.org/en/461601591649316722/Projected-poverty-impacts-of-COVID19.pdf (2020).

21. Shan, Y. et al. Impacts of COVID-19 and fiscal stimuli on global emissions and the Paris Agreement. Nat. Clim. Chang. 11, 200-206 (2021).

22. Ang, B. W. The LMDI approach to decomposition analysis: a practical guide. Energy Policy 33, 867871 (2005).

23. Ang, B. W. LMDI decomposition approach: A guide for implementation. Energy Policy 86, 233-238 (2015).

24. Kissler, S. M., Tedijanto, C., Goldstein, E., Grad, Y. H. \& Lipsitch, M. Projecting the transmission dynamics of SARS-CoV-2 through the postpandemic period. Science 368, 860-868 (2020).

25. Zeng, Z., Guan, D., Steenge, A. E., Xia, Y. \& Mendoza-Tinoco, D. Flood footprint assessment: a new approach for flood-induced indirect economic impact measurement and post-flood recovery. Journal of Hydrology 579, 124204 (2019).

26. International Institute for Applied Systems Analysis. Greenhouse Gas - Air Pollution Interactions and Synergies (GAINS) - IEA WEO 2019 SPS/SDS scenarios. (2020).

27. Amann, M. et al. Reducing global air pollution: the scope for further policy interventions. Philosophical Transactions of the Royal Society A: Mathematical, Physical and Engineering Sciences 378, 20190331 (2020).

28. Rafaj, P. et al. Air quality and health implications of $1.5^{\circ} \mathrm{C}-2{ }^{\circ} \mathrm{C}$ climate pathways under considerations of ageing population: a multi-model scenario analysis. Environ. Res. Lett. 16, 045005 (2021).

29. Rubin, E. et al. IPCC Special Report on Carbon dioxide Capture and Storage: Technical Summary. 34.

30. Varun, Bhat, I. K. \& Prakash, R. LCA of renewable energy for electricity generation systems-A review. Renewable and Sustainable Energy Reviews 13, 1067-1073 (2009).

31. Abdallah, L. \& El-Shennawy, T. Reducing Carbon Dioxide Emissions from Electricity Sector Using Smart Electric Grid Applications. Journal of Engineering 2013, 1-8 (2013).

32. Mouli, G. R. C. et al. Economic and CO2 Emission Benefits of a Solar Powered Electric Vehicle Charging Station for Workplaces in the Netherlands. in 2016 IEEE Transportation Electrification Conference and Expo (ITEC) 1-7 (IEEE, 2016). doi:10.1109/ITEC.2016.7520273.

33. International Energy Agency. World Energy Balance. (2018).

34. World Bank. World Bank national accounts data. (2020).

35. Aguiar, A., Chepeliev, M., Corong, E. L., McDougall, R. \& Mensbrugghe, D. van der. The GTAP Data Base: Version 10. Journal of Global Economic Analysis 4, 1-27 (2019).

36. GAINS Model. https://gains.iiasa.ac.at/models/.

37. IEA. World Energy Model. https://www.iea.org/reports/world-energy-model (2019). 
38. Riahi, K. et al. The Shared Socioeconomic Pathways and their energy, land use, and greenhouse gas emissions implications: An overview. Global Environmental Change 42, 153-168 (2017).

39. KC, S. \& Lutz, W. The human core of the shared socioeconomic pathways: Population scenarios by age, sex and level of education for all countries to 2100. Global Environmental Change 42, 181-192 (2017).

40. Cuaresma, J. C. Income projections for climate change research: A framework based on human capital dynamics. Global Environmental Change 42, 226-236 (2017).

41. Jiang, L. \& O'Neill, B. C. Global urbanization projections for the Shared Socioeconomic Pathways. Global Environmental Change 42, 193-199 (2017).

42. Leimbach, M., Kriegler, E., Roming, N. \& Schwanitz, J. Future growth patterns of world regions - A GDP scenario approach. Global Environmental Change 42, 215-225 (2017).

43. Dellink, R., Chateau, J., Lanzi, E. \& Magné, B. Long-term economic growth projections in the Shared Socioeconomic Pathways. Global Environmental Change 42, 200-214 (2017).

44. Huppmann, D. et al. IAMC $1.5^{\circ} \mathrm{C}$ Scenario Explorer and Data hosted by IIASA. (Integrated Assessment Modeling Consortium \& International Institute for Applied Systems Analysis, 2018). doi:10.22022/SR15/08-2018.15429.

\section{Figures}



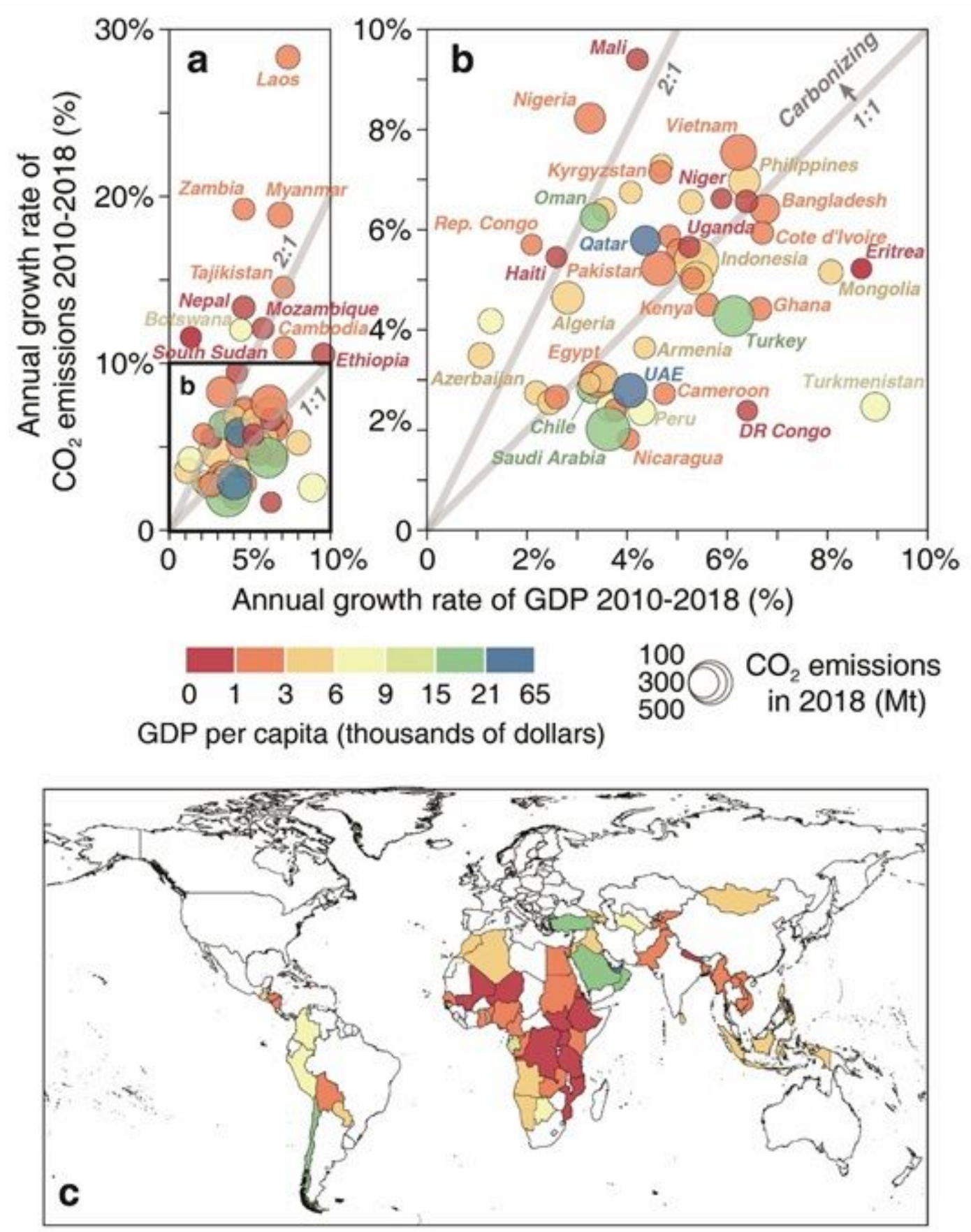

\section{Figure 1}

Relative increase of CO2 emissions and GDP in 2018 over 2010. Relative increase of GDP and CO2 of the 59 countries (due to lack of data, data presented for South Sudan are based on 2012-2015, Eritrea on 2010-2011, and DR Congo on 2010-2017, respectively) with fast-growing emissions in 2018 over levels of 2010 are shown in the panel (a). Each bubble represents a country, plotted by GDP increase in 2018 relative to the level of 2010 on the horizontal and relative CO2 emission increase on the vertical. The bubbles of countries with a less-than-100\% emission increase (within the black dashed box) in the lower left part are zoomed in on the right panel (b). The two grey lines with slopes of 1 (lower) and 2 (upper) mean the $\mathrm{CO} 2$ emission growth rate is the same as or twice the rate of the GDP growth. Countries plotted above the 1:1 line are carbonizing. The size of the bubbles represents the amount of $\mathrm{CO} 2$ emissions in 
2018. The colors represent the per capita GDP of the countries, red for the lower and blue for the higher, with the same color shown in the map (c).

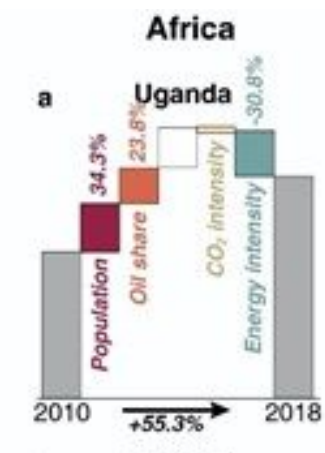

Latin America

East/South Asia
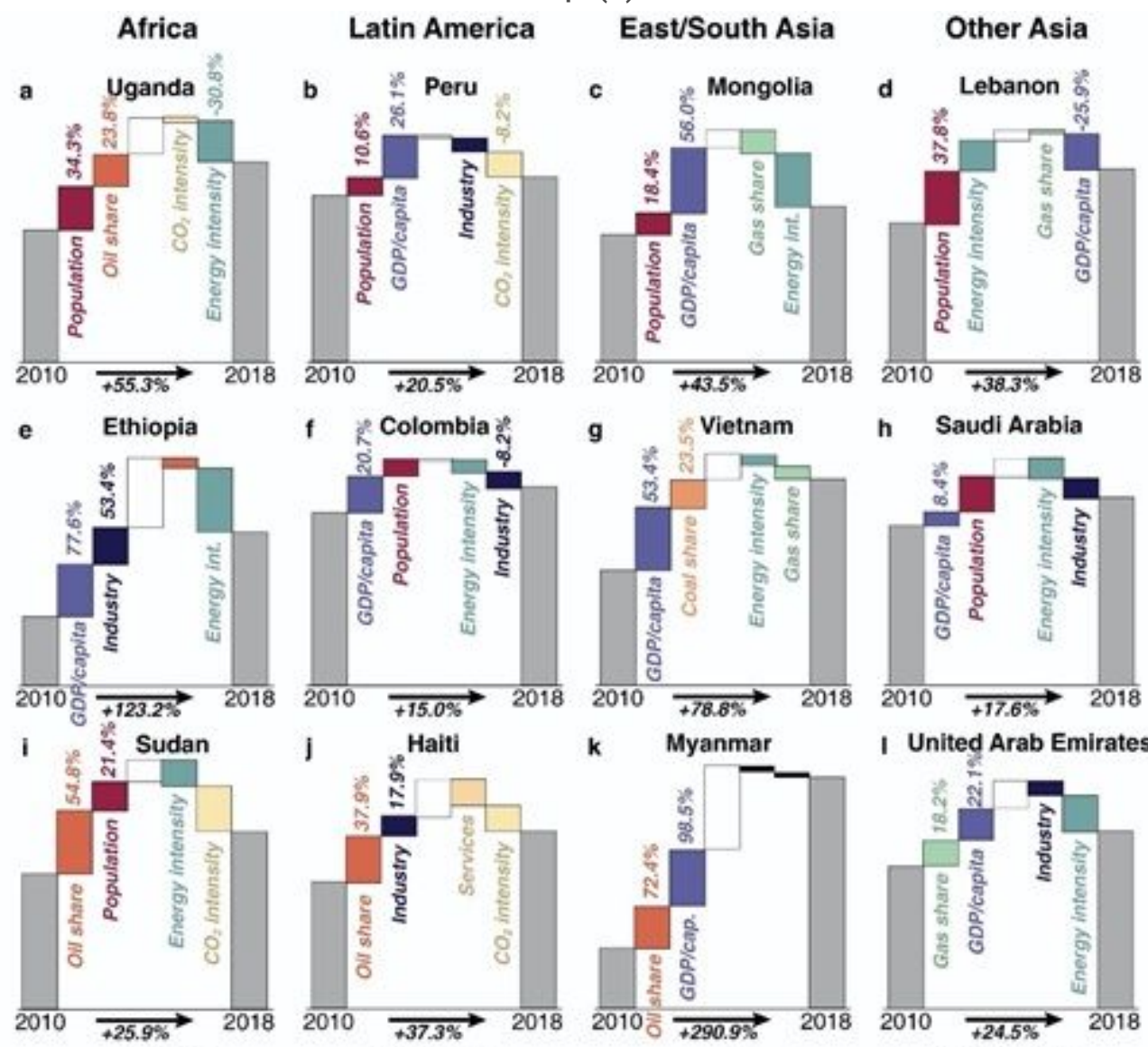

k Myanmar
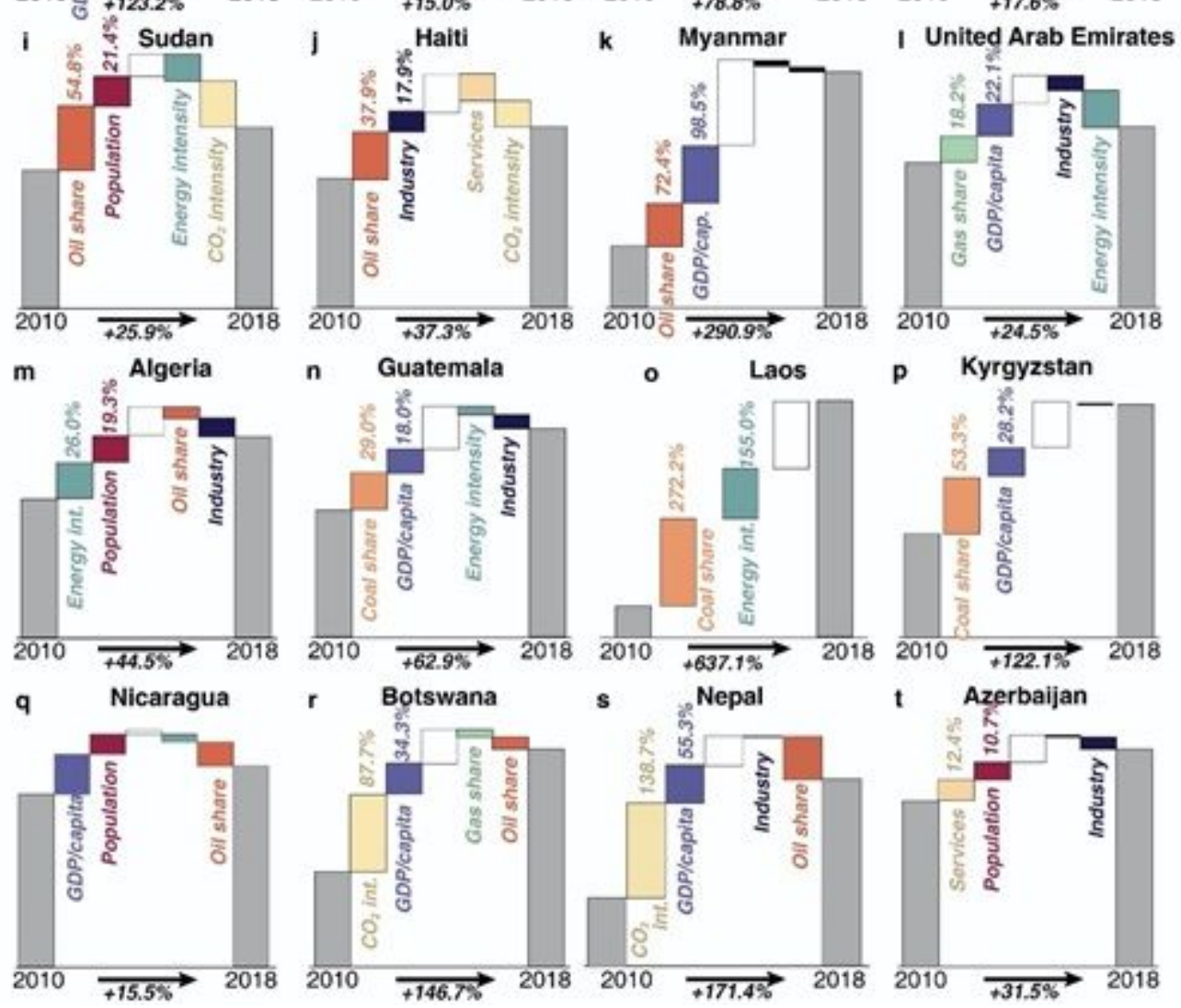

Figure 2

Case countries with surging emissions and their drivers, emissions in Mt. The waterfalls show the drivers of emission growth over 2010-2018, including drivers increasing consumption (population, GDP per capita), drivers affecting economic structure (industrial structure, i.e. share of the value added of primary, secondary, and tertiary industry, and the energy intensity of GDP), and drivers affecting carbon intensity (energy structure, i.e. share of consumption of coal, oil, natural gas and other fuel, and $\mathrm{CO} 2$ emission 
intensity of energy). Each country has their two main drivers and two main inhibitors shown, and the emission increased from the level of 2010 to that of 2018.
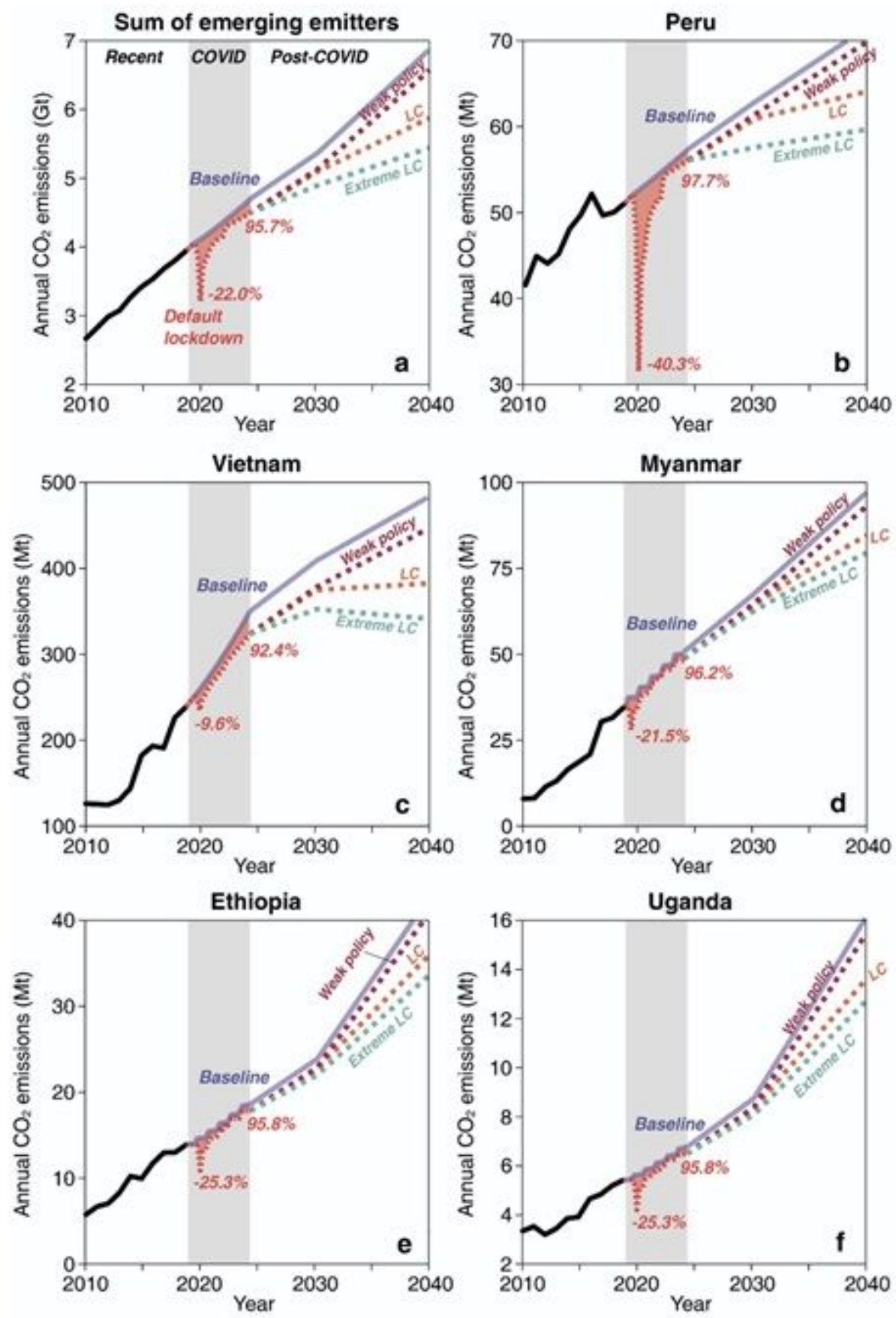

Figure 3

Recent and projected emissions of selected countries and aggregated emerging emitters combined. Among those countries whose emissions have been growing most rapidly, COVID-related impacts may cause substantial decreases in emissions (red). However, these decreases are temporary and across a range of scenarios have relatively little effect on emissions after 2024, when emissions continue to rise. After 2024, the dashed lines in dark red, orange, and green show the trajectory of emissions after the default lockdown of COVID-19, while the purple solid line shows that without COVID impact. Comparatively larger differences in projected cumulative emissions are related to whether countries 
adopt low-carbon technologies (orange), extreme low-carbon technologies (green) or proceed with weak climate policies (dark red).
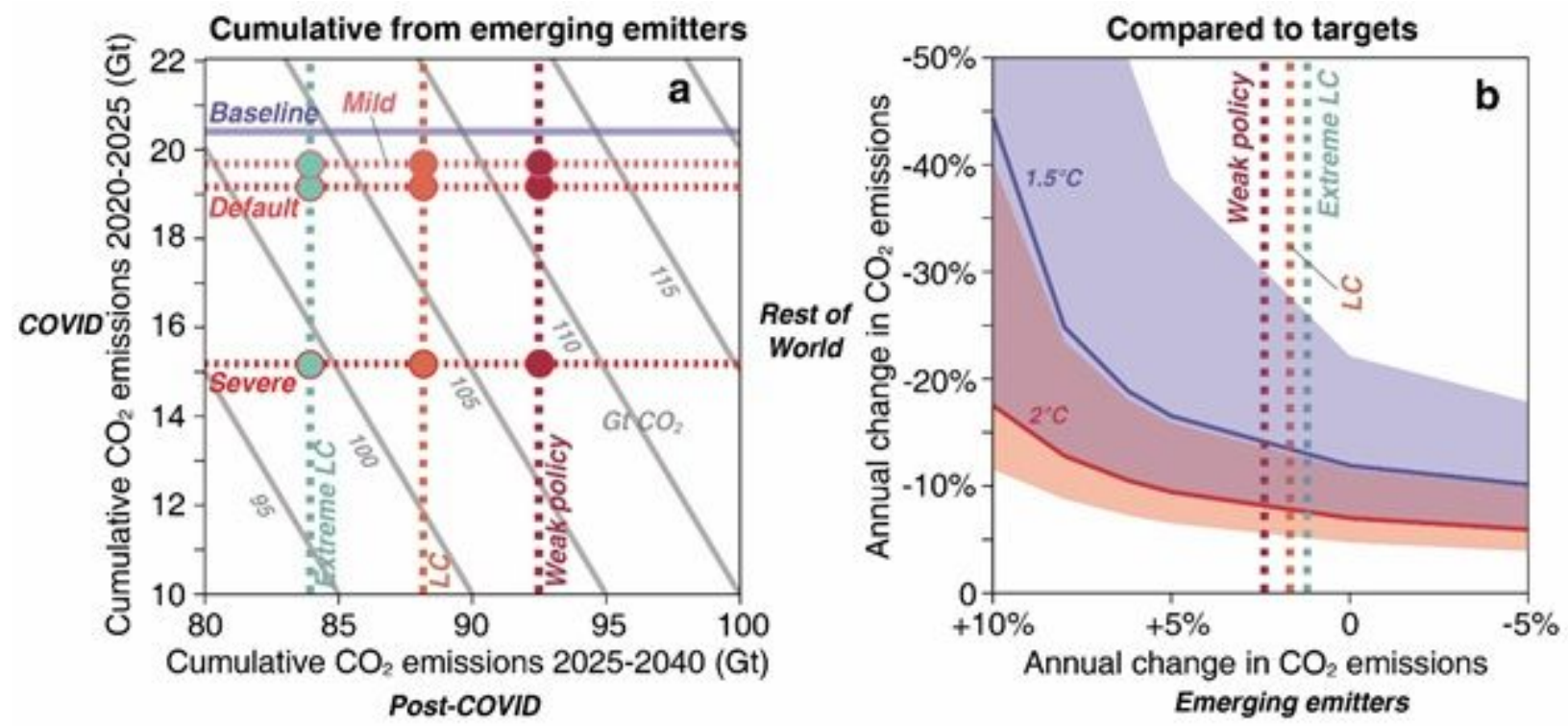

Figure 4

Comparisons of emerging emitter scenarios. a, Cumulative $\mathrm{CO} 2$ emissions from emerging emitters 20202040 (contours) depend upon both projected COVID recovery (2020-2024, dashed horizontal lines) and post-COVID climate mitigation efforts (2025-2040, dashed vertical lines). The points of the intersections show the combination of COVID scenarios and post-COVID scenarios, and the contours help to identify the cumulative emissions. $b$, Annual changes in emissions from emerging emitters have important implications for the rate of emissions reductions required in the rest of the world to limit global warming below $1.5^{\circ} \mathrm{C}$ or $2^{\circ} \mathrm{C}$. The purple line shows the combinations of the annual changes of emissions of the two types of countries to reach the $1.5{ }^{\circ} \mathrm{C}$ target, and the shadow shows the 5-95 percentile range for that. The red line and shadow represents the same for the $2^{\circ} \mathrm{C}$ target. Dark red, orange, and green vertical dashed lines represent the annual growth rate of the emerging emitters under the scenarios of weak policy, low carbon, and extreme low carbon, respectively.

\section{Supplementary Files}

This is a list of supplementary files associated with this preprint. Click to download.

- SupportingInformation0329.docx

- SupplementaryData1.xlsx

- SupplementaryData2.xlsx

- SupplementaryData3.xlsx 